\title{
PENGARUH STAKEHOLDER PERSPECTIVE DALAM PENERAPAN ERP : A SYSTEMATIC LITERATURE REVIEW
}

\author{
Afifah Nurul Izzati ${ }^{1}$, Nina Fadilah Najwa ${ }^{2}$ \\ ${ }^{1}$ Magister Sistem Informasi, Fakultas Teknologi Informasi dan Komunikasi, Institut Teknologi Sepuluh \\ Nopember Surabaya \\ ${ }^{2}$ Magister Sistem Informasi, Fakultas Teknologi Informasi dan Komunikasi, Institut Teknologi Sepuluh \\ Nopember Surabaya \\ Email: ${ }^{1}$ fifah.afifah26@gmail.com, ${ }^{2}$ nina.fadilah.najwa16@mhs.is.its.ac.id
}

(Naskah masuk: ddmmmyyyy, diterima untuk diterbitkan: ddmmmyyyy)

\begin{abstract}
Abstrak
Penerapan ERP pada perusahaan mempunyai banyak manfaat. Dengan menerapkan ERP, perusahaan mampu meningkatkan produktifitas perusahaan dengan cara mengurangi biaya pengeluaran dan meningkatkan pendapatan. Namun pada penerapan ERP dapat mengalami kesuksesan atau mengalami kegagalan. Oleh karena itu, perlu mempertimbangkan critical succes factor yang berpengaruh terhadap penerapan ERP, salah satunya critical success factor pada penerapan ERP adalah stakeholder perspective. Untuk mengetahui pengaruh stakeholder, maka dilakukan kajian ulang beberapa paper dengan jumlah 24 paper yang ditemukan. Dari kajian ulang didapatkan peninjauan pengaruh stakeholder perspective pada penerapan ERP yang dapat dilihat dari tiga sudut pandang, yaitu studi kasus mengenai pengaruh stakeholder perspective dalam penerapan ERP, faktorfaktor dari stakeholder perspective yang berpengaruh pada proses penerapan ERP meliputi komunikasi, dukungan stakeholder (meliputi dukungan top management dan tim proyek), kesiapan sumber daya manusia, dan beberapa cara atau solusi yang dapat digunakan dalam mencegah atau menangani masalah yang muncul berdasarkan faktor-faktor dari stakeholder perspective yang berpengaruh pada proses penerapan ERP.
\end{abstract}

Kata kunci: ERP, Stakeholder Perspective, Faktor - Faktor Stakeholder Perspective

\section{THE EFFECT OF STAKEHOLDER PERSPECTIVE IN ERP IMPLEMENTATION: A SYSTEMATIC LITERATURE REVIEW}

\begin{abstract}
Implementation of ERP in the company has many benefits. By implementing ERP, the company is able to increase the productivity of the company by reducing the cost of spending and increasing revenue.But on the implementation of ERP can experience success or failure. Therefore, it is necessary to consider the critical succes factor that influences the implementation of ERP, one of which is critical success factor in the application of ERP is stakeholder perspective. To determine the influence of stakeholders, a review of several papers with 24 papers was found. From the review it was found that the review of the influence of stakeholder perspective on ERP implementation can be seen from three perspectives, ie case study on influence of stakeholder perspective in ERP implementation, factors from stakeholder perspective that influence on ERP implementation process include communication, stakeholder support (top management and project teams), human resource readiness, and some ways or solutions that can be used in preventing or dealing with emerging problems based on factors from stakeholder perspectives that affect the ERP implementation process.
\end{abstract}

Keywords: ERP, Stakeholder Perspective, Stakeholders Perspectives Factors

\section{PENDAHULUAN}

Seiring dengan berkembangnya teknologi informasi saat ini, maka akan berpengaruh terhadap perusahaan dalam melakukan proses pengambilan keputusan. Dengan dukungan teknologi informasi pada suatu perusahaan, diharapkan mampu meningkatkan efektifitas dan efisiensi pada proses bisnisnya, sehingga dapat mengurangi biaya pengeluaran dan dapat meningkatkan pendapatannya. Salah satu teknologi informasi yang diterapkan pada perusahaan adalah Enterprise 
Resource Planning (ERP). ERP adalah suatu software yang ditujukan untuk enterprise dalam membantu organisasi untuk mengelola dan membuat efektif penggunaan sumber daya (materials, human resources, finance, dan sebagainya) dengan menyediakan solusi terintegrasi untuk mengolah informasi yang dibutuhkan (Saini, Nigam, \& Misra, 2013). ERP yang diterapkan pada suatu perusahaan atau organisasi mempunyai fungsi untuk membantu perusahaan atau organisasi dalam melakukan koordinasi dan integrasi beberapa informasi aktifitas bisnis yang mempunyai area fungsional yang berbeda untuk memperoleh gambaran besar bisnis secara keseluruhan. Penerapan sistem ERP menjadi lebih penting bagi bisnis untuk mendapatkan efisiensi dan kompetitif. ERP mempunyai beberapa modul yang saling terintegrasi pada divisi di organisasi, sehingga memudahkan dalam mengelola, menyimpan, dan memantau aktivitas bisnis secara keseluruhan.

Penerapan ERP pada organisasi mempunyai banyak manfaat. Dengan menerapkan ERP, organisasi mampu meningkatkan produktifitas organisasi dengan cara mengurangi biaya pengeluaran dan meningkatkan pendapatan. Adanya integrasi informasi pada setiap divisi pada area fungsional organisasi membuat proses bisnis menjadi lebih efektif dan dapat mengurangi biaya yang dikeluarkan untuk mempekerjakan tenaga kerja tambahan, karena beberapa aktifitas dapat ditangani oleh sistem. Manfaat ERP dapat dirasakan ketika penerapan ERP pada organisasi terlaksana dengan sukses.

Meskipun suatu organisasi mampu mendapakan banyak manfaat dari kesuksesan penerapan sistem ERP, namun tingkat kegagalan dalam proyek penerapan ERP tergolong tinggi (Nour, Mouakket, Mohamed, \& Samar, 2011). Pada suatu penelitian yang merujuk pada laporan Chang (2004) menjelaskan bahwa 90\% dari penerapan ERP yang dilakukan telah melebihi biaya dan waktu yang ditargetkan dan inisiasi perusahaan menunjukkan tingkat kegagalan mencapai $67 \%$ dalam mencapai tujuan dan dikatakan tidak sukses (Shaul \& Tauber, 2012). Untuk memaksimalkan kemungkinan kesuksesan penerapan ERP, penting untuk memahami sepenuhnya komponen apa yang membentuk critical success factor, bagaimana mencapainya, dan critical success factor lainnya yang diidentifikasi oleh pakar industri sebagai hal yang penting bagi implementasi ERP (Hogan, 2014). Terdapat beberapa critical success factor yang mempengaruhi kesuksesan penerapan ERP, salah satu critical success factor yang berpengaruh adalah dilihat dari sudut pandang stakeholder.

Pada beberapa penelitian studi kasus (Dezdar \& Ainin, 2011)(Saini et al., 2013), menjelaskan bahwa penerapan ERP yang dipengaruhi oleh faktor stakeholder. Sehingga, pada proses penerapan ERP perlu melakukan identifikasi beberapa critical success factor salah satunya dilihat dari sudut pandang stakeholder. Tujuan dari penelitian ini adalah mengidentifikasi faktor yang mempengaruhi kesuksesan pada proses penerapan ERP dilihat dari sudut pandang stakeholder.

Untuk mengetahui pengaruh stakeholder, maka penulis melakukan tinjauan ulang dari beberapa penelitian sebelumnya untuk membahas secara menyeluruh tentang pengaruh stakeholder terhadap penerapan ERP. Pengaruh stakeholder pada penerapan ERP dapat dilihat dari tiga sudut pandang, yaitu dari studi kasus mengenai pengaruh stakeholder perspective dalam penerapan ERP, faktor-faktor dari stakeholder perspective yang berpengaruh pada proses penerapan ERP, dan beberapa cara yang dapat digunakan dalam menangani stakeholder perspective agar tercapai keberhasilan penerapan ERP.

\section{TINJAUAN PUSTAKA}

\subsection{Enterprise Resource Planning (ERP)}

Enterprise Resource Planning(ERP) adalah suatu perangkat lunakyang ditujukan untuk perusahaanatau organisasi dalam membantu organisasi untuk mengelola dan membuat efektif penggunaan sumber daya (materials, human resources, finance, dan sebagainya) dengan menyediakan solusi terintegrasi untuk mengolah informasi yang dibutuhkan (Saini et al., 2013). ERP terdiri dari kumpulan perangkat lunak yang berbeda yang digunakan untuk mengintegrasikan fungsi bisnis di perusahaan atau organisasi(Bajahzar \& Alqahtani, 2013).

ERP diterapkan pada suatu organisasi untuk mendapatkan manfaat dari penerapannya, sehingga dapat meningkatkan kinerja organisasi. Selain itu, banyak perusahaan di seluruh dunia membeli paket perangkat lunak komersial yang berbeda, seperti sistem enterprise resource planning (ERP), untuk memperbaiki proses dan menurunkan biaya(Nour et al., 2011). Menurut Abdullah Bajahzar et al, manfaat penerapan ERP ada enam, yaitu yang pertama adalah penggunaan sistem ERP dapat meningkatkan efisiensi dalam sebuah organisasi, kedua adalah penggunaan sistem ERP mengarah pada pelaporan yang lebih baik, berbagai laporan yang ada dapat dihasilkan dengan menggunakan sistem ini, ketiga adalah untuk institusi atauorganisasi yang besar, penggunaan sistem ERP mengarah pada peningkatan komunikasi di berbagai departemen, keempat adalah salah satu kebutuhan penggunaan sistem ERP yaitu dengan menggunakan data yang lebih akurat dan relevan, kelima adalah memungkinkan pengelolaan dan pemantauan proses yang efisien dalam organisasi, dan keenam yaitu data yang digunakan dalam sistem tersebut memiliki standar yang sangat tinggi, sehingga memastikan bahwa produk atau layanan yang ditawarkan berdasarkan data tersebut berkualitas tinggi. 


\subsection{Critical Success Factor (CSF)}

Pada penerapan ERP, untuk mendapatkan banyak manfaat yang dihasilkan maka perlu memastikan proses penerapan ERP berjalan sukses. Untuk memastikan proses penerapan ERP berjalan sukses, perlu memahami beberapa komponen yang berpengaruh terhadap proses penerapan ERP. Banyak faktor yang dipertimbangkan dalam kesuksesan penerapan ERP. Berdasarkan hal tersebut, banyak penulis yang menyoroti critical success factor (CSF) pada proyek penerapan ERP (Shaul \& Tauber, 2012). Mereka yakin bahwa pemahaman yang lebih besar terhadap berbagai critical success factorakan meningkatkan keseluruhan peluang keberhasilan penerapan ERP (Finney, 2011). Untuk memudahkan dalam identifikasi critical success factor pada penerapan ERP, maka critical success factor dikelompokkan menjadi tiga, yaitu organizational, country-related dan technical(Alsulami \& Scheepers, 2016).Critical success factor menjadi bagian paling penting yang perlu diidentifikasi dalam penerapan ERP, karena dapat berpengaruh pada kegagalan atau keberhasilan penerapan ERP. Pada kegagalan penerapan ERP, perusahaan akan cukup mengalami kerugian akibat penerapannya. Sedangkan pada keberhasilan penerapan ERP, perusahaan akan mendapatkan keuntungan dari penerapannya (Morris \& Venkatesh, 2010).

\subsection{Perspektif Stakeholder}

Salah satu critical success factor yang berpengaruh pada proses penerapan ERP adalah dilihat dari sudut pandang stakeholder.Salah satukunci utama dalam penerapan ERP adalah bagaimana memastikan semua pihak yang terlibat dalam pelaksanaannya jelas mengenai peran mereka di semua tahap pelaksanaannya(Waiel AI-Rashid', 2012). Beberapa peneliti telah mengakui pentingnya stakeholder dalam CSF(Nour et al., 2011).

Proyek penerapan ERP begitu kompleks, sehingga penting proyek ERP memenuhi kebutuhan dengan memberi nilai kepada stakeholder, dengan memastikan proyek berjalan dengan baik dan untuk memastikan harapan stakeholder terpenuhi(Hogan, 2014). Sehingga untuk memudahkan indentifikasi, stakeholder dapat dibedakan menjadi dua kategori yaitu internal dan eksternal. Stakeholder merupakan perpaduan antara karyawan lintas departement, pembuat keputusan, serta pihak pelaksana penerapan ERP (konsultan) (Saini et al., 2013). Oleh karena itu karena stakeholder sangat berpengaruh pada peningkatan proses penerapan ERP, maka sudut pandang stakeholder harus menjadi pertimbangan dalam proses penerapan ERP.

\section{METODOLOGI PENELITIAN}

Metodologi merupakan suatu pendekatan yang digunakan dalam melaksanakan tinjauan literatur
ini(Achimugu, Selamat, Ibrahim, \& Mahrin, 2014). Berdasarkan Gambar 1, metodologi terdiri dari lima tahap, yaitu merumuskan masalah, mencari literatur, memilah hasil pencarian literatur, melakukan analisis, dan memahami hasil pencarian literatur. Pada tahap pertama adalah merumuskan masalah yang terdiri dari beberapa pertanyaan penelitian (research questions) yang dirumuskan berdasarkan tujuan dari tinjauan literatur ini. Tahap kedua adalah merencanakan strategi pencarian literatur yang dirancang sesuai dengan pertanyaan penelitian yang dirumuskan yang terdiri dari identifikasi kata kunci pencarian dan pencarian literatur pada lembaga penyedia literatur.Tahap ketiga adalah memilah hasil pencarian literatur yang telah didapatkan berdasarkan standar pemilahan yang sudah ditentukan. Tahap ke empat adalah melakukan analisis beberapa literatur dari hasil pencarian yang telah dipilah sebelumnya. Tahap kelima adalah memahami hasil pencarian yang telah dirangkum pada tahap analisis.

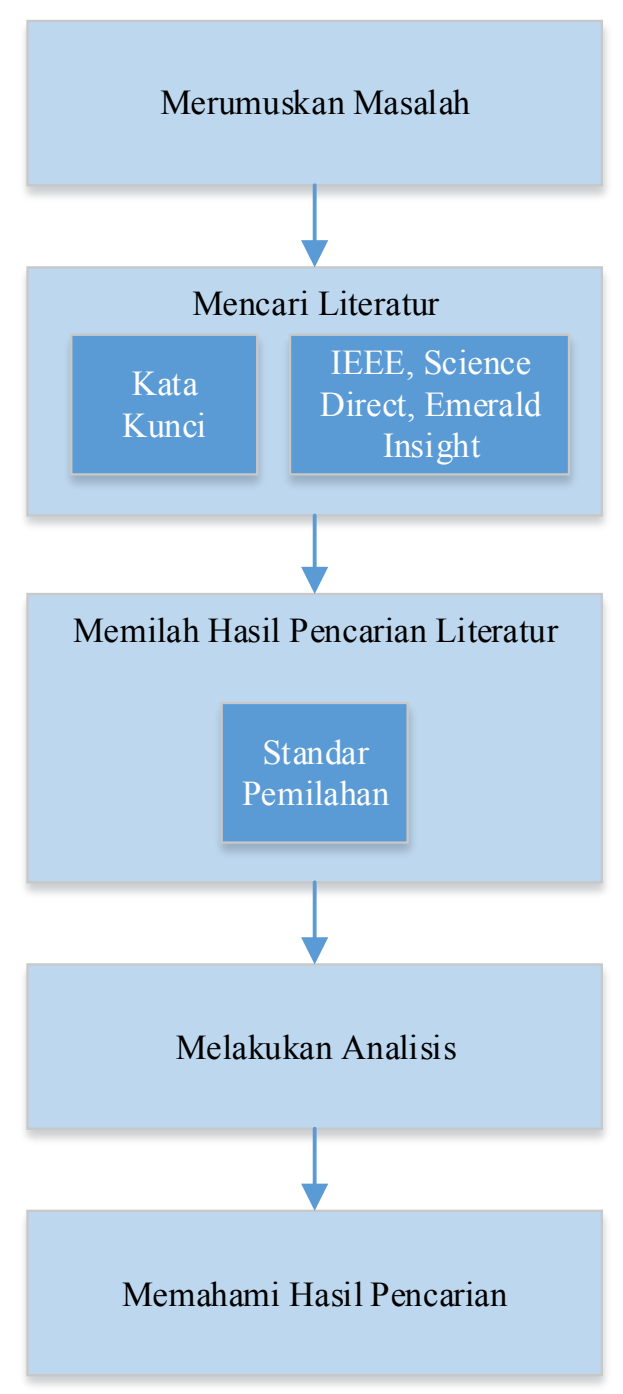

Gambar 1. Metodologi literatur review(Achimugu, Selamat, Ibrahim, \& Mahrin, 2014) 


\subsection{Merumuskan Masalah}

Tujuan dari tinjauan literaturini adalah untukmengetahui pengaruh faktor-faktor stakeholder perspective terhadap kesuksesan penerapan ERP.Untuk mencapai tujuan tersebut, maka perlu merumuskan masalah dengan cara merumuskan beberapa pertanyaan penelitian atau research questions(RQs). Dari tahap ini diperoleh tiga poin utama $R Q s$, yaitu :

1. $R Q 1$ : Bagaimana pengaruh stakeholder perspective terhadap penerapan ERP ditinjau dari beberapa studi kasus ?

2. $R Q 2$ : Apa saja faktor-faktor dari stakeholder perspective yang berpengaruh terhadap proses penerapan ERP ?

3. RQ3: Apa solusi yang dapat digunakan dalam menangani stakeholder perspective agar tercapai keberhasilan penerapan ERP.

\subsection{Mencari Literatur}

Tahap kedua adalah mencari literatur yang terdiri dari jurnal dan hasil konferensi yang berkaitan dengan pengaruh stakeholder perspective pada penerapan ERP. Pada pencarian sumber literatur fokus pada kata kunci ERP implementation, ERP critical success factor, dan ERP implementation from stakeholder perspective. Literatur dapat diperoleh dari beberapa lembaga penyedia jurnal internasional, seperti science direct, emerald insight, dan IEEE.

\begin{tabular}{|l|l|l|l|}
\hline Tabel 1. Hasil Pencarian Literatur \\
\hline Kata Kunci & Science Direct & IEEE & Emerald \\
\hline $\begin{array}{l}\text { ERP Implementation } \\
\text { Imritical }\end{array}$ & 14,259 & 522 & 1525 \\
\hline $\begin{array}{l}\text { ERP } \\
\text { Success Factor }\end{array}$ & 509 & 66 & 543 \\
\hline $\begin{array}{l}\text { Implementation } \\
\text { from stakeholder } \\
\text { perspective }\end{array}$ & 64,346 & 117 & 509 \\
\hline
\end{tabular}

Dari hasil pencarian tersebut, langkah selanjutnya adalah memilah hasil pencarian literatur yang sesuai untuk mendapatkan literatur yang akan digunakan pada literatur review ini.

\subsection{Memilah Hasil Pencarian Literatur}

Tahap ketiga adalah memilah hasil pencarian dengan cara menyaring jurnal dan hasil konferensi yang telah didapatkan berdasarkan standar yang sudah ditetapkan. Standar yang ditentukan adalah sebagai berikut :

1. Hasil penemuanliteratur terdiri dari jurnal dan hasil konferensi harus secara jelas menjawab permasalahan berdasarkan perumusan masalah atau research questions(RQs)yangdiulas pada tinjauan ini.
2. Hasil pencarian harus diperoleh dari beberapa jurnal dan hasil konferensi yang terpercaya.

3. Tahun publikasi pada hasil pencarian adalah 7 tahun terakhir, yaitu sejak tahun 2010 hingga 2017.

Literatur yang didapatkan dilakukan penyaringan berdasarkan tahun publikasi dan kriteria dalam pemilahan hasil pencarian literatur. Selanjutnya, melakukan eliminasi terhadapa jurnal ataupun paper yang duplikat. Sehingga, dari hasil pencarian beberapa literatur yang terdiri dari jurnal dan hasil konferensi, telah ditemukan sejumlah 24 literatur. Hasil dari beberapa literatur yang telah ditemukan digunakan sebagai acuan dalam melakukan analisis.

\begin{tabular}{|l|l|l|l|}
\multicolumn{1}{|c|}{ Tabel 2. Hasil seleksi } \\
\hline Basis Data & $\begin{array}{c}\text { Total } \\
\text { Retrieved }\end{array}$ & $\begin{array}{l}\text { Inclusion } \\
\text { (tahun) }\end{array}$ & $\begin{array}{l}\text { Final } \\
\text { Selection }\end{array}$ \\
\hline Science Direct & 83,614 & 55.450 & 3 \\
\hline IEEE & 705 & 422 & 3 \\
\hline Emerald Insight & 2577 & 1384 & 11 \\
\hline $\begin{array}{l}\text { Referensi } \\
\text { Relevan }\end{array}$ & & & 7 \\
\hline
\end{tabular}

Dari 24 literatur yang telah ditemukan (tabel 2), selanjutnya dilakukan proses pemilahan berdasarkan metodologi. Hasil literatur yang sudah dipilah digunakan sebagai acuan utama dalam melakukan tinjauan ini. Hasil dari proses pemilahan literatur diperoleh sejumlah 22 literatur yang terdiri dari jurnal dan hasil konferensi.

\subsection{Melakukan Analisis}

Tahap keempat adalah melakukan analisis dari hasil pencarian literatur yang sudah dipilah pada tahap ketiga. Analisis dilakukan dengan cara mengumpulkan dan merangkum beberapa hasil pencarian literatur yang berhubungan dengan pengaruh stakeholder perspective pada penerapan ERP. Untuk mempermudah dalam melakukan proses analisis, maka dilakukan pengelompokkan literatur berdasarkan jenis dari isi pembahasannya sesuai dengan rumusan masalah. Terdapat tiga jenis pengelompokkan literatur, yaitu mengenai critical success factor penerapan ERP, pengaruh stakeholder perspective pada penerapan ERP, dan studi kasus pengaruh stakeholder pada penerapan ERP.

\subsection{Memahami Hasil Pencarian}

Tahap kelima adalah tahap terakhir yang mencakup dari semua tahap sebelumnya. Pada tahap ini, diharuskan memahami pencarian yang sudah dilakukan pada tahap sebelumnya. Sehingga pada tahap ini dapat dilakukan penyusunan hasil pembahasan tinjauanmengenai pengaruh stakeholder perspective pada penerapan ERP. Berdasarkan rumusan masalah, maka tinjauan literatur ini dapat 
dilihat dari tiga sudut pandang, yaitu pengaruh stakeholder perspective terhadap penerapan ERPditinjau dari beberapa studi kasus, faktor-faktor stakeholder perspective dalam penerapan ERP, dan solusi . Beberapa literatur yang didapatkan digunakan untuk membahas mengenai pengaruh stakeholder perspective pada penerapan ERP.

\section{HASIL}

\subsection{Hasil Pencarian dan Kategorisasi}

Berdasarkan tahapan pencarian yang dilakukan, maka diperoleh hasil pencarian literatur. Pada Gambar 2 menunjukkan jumlah perbandingan literatur yang ditemukan di awal dengan jumlah literaturyang sudah dipilah di akhir.

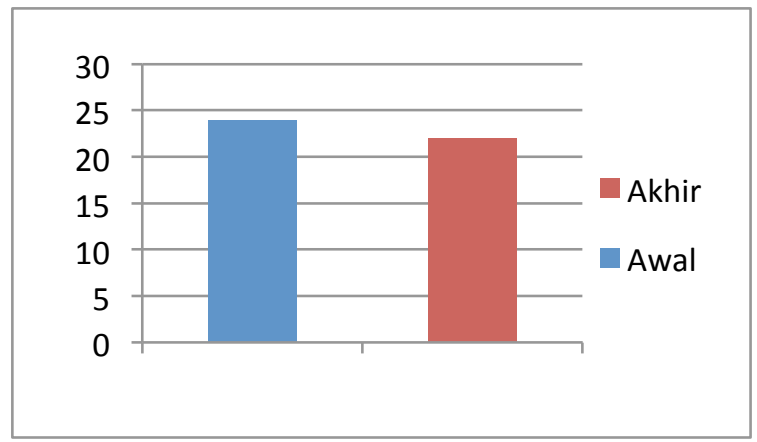

Gambar 2. Perbandingan Jumlah Literatur

Sejumlah 22 paper yang sudah dipilah dan diterima untuk dijadikan acuan utama, selanjutnya akan dilakukan pengelompokan. Pengelompokan didasarkan pada isi dari paper yang dibahas. Penulis melakukan pengelompokan menjadi tiga jenis dari isi yang dibahas, yaitu mengenai critical success factor penerapan ERP,pengaruh stakeholder perspective penerapan ERP, dan studi kasus penerapan ERP. Tabel 3 menunjukkan hasil pengelompokkan paper berdasarkan jenis dari isi yang dibahas dalam paper. Pada gambar 3 menunjukkan hasil perbandingan jumlah paperdarimasing-masing jenis dari hasil pengelompokan. Pada pengelompokkan paper yang membahas mengenai critical success factor penerapan ERP sejumlah 8, paper yang membahas pengaruh stakeholder perspective pada penerapan ERP sejumlah 16, paper yang membahas studi kasus sejumlah10.

Tabel 3. Hasil Pengelompokkan Paper Berdasarkan Jenis Dari Isi

\begin{tabular}{|l|l|l|}
\multicolumn{1}{|c|}{ Kategori } & \multicolumn{1}{|c|}{ Paper } & Jumlah \\
\hline Critical success factor & (Saini et al., 2013), & 8 \\
penerapan ERP & (Nour et al., 2011), & \\
& (Shaul \& Tauber, & \\
& 2012), & \\
& (Hogan, 2014), & \\
& (Dezdar \& Ainin, & \\
& 2011), & \\
& (Bajahzar \& & \\
& Alqahtani, 2013), & \\
& (Alsulami \& & \\
\end{tabular}

\begin{tabular}{|c|c|c|}
\hline Kategori & Paper & Jumlah \\
\hline & $\begin{array}{l}\text { Scheepers, 2016), } \\
\text { (Maguire, Ab, \& } \\
\text { Maguire, 2010) }\end{array}$ & \\
\hline $\begin{array}{l}\text { Pengaruh stakeholder } \\
\text { perspective pada } \\
\text { penerapan }\end{array}$ & $\begin{array}{l}\text { (Saini et al., 2013), } \\
\text { (Hogan, 2014), } \\
\text { (Shaul \& Tauber, } \\
\text { 2012), } \\
\text { (Dezdar \& Ainin, } \\
\text { 2011), } \\
\text { (Bajahzar \& } \\
\text { Alqahtani, 2013), } \\
\text { (Finney, 2011), } \\
\text { (Morris \& Venkatesh, } \\
\text { 2010), } \\
\text { (Waiel AI-Rashid', } \\
\text { 2012), } \\
\text { (Maguire et al., 2010), } \\
\text { (Shah, 2011), } \\
\text { (Bintoro, 2015), } \\
\text { (Ali \& Miller, 2017), } \\
\text { (Gallagher, Worrell, \& } \\
\text { Mason, 2012), } \\
\text { (Boonstra \& Boonstra, } \\
\text { 2016), } \\
\text { (Drummond \& Araujo, } \\
\text { 2016),(Matende \& } \\
\text { Ogao, 2013) }\end{array}$ & 16 \\
\hline Studi Kasus & $\begin{array}{l}\text { (Saini et al., 2013), } \\
\text { (Shaul \& Tauber, } \\
\text { 2012), } \\
\text { (Finney, 2011), } \\
\text { (Waiel AI-Rashid', } \\
\text { 2012), } \\
\text { (Maguire et al., 2010), } \\
\text { (Shah, 2011), } \\
\text { (Gallagher et al., } \\
\text { 2012), } \\
\text { (Boonstra \& Boonstra, } \\
\text { 2016), } \\
\text { (Drummond \& Araujo, } \\
\text { 2016), (Xie, James } \\
\text { Allen, \& Ali, 2014) }\end{array}$ & 10 \\
\hline
\end{tabular}

Dapat dilihat dari tabel diatas, bahwasanya pada kategori pengaruh stakeholder perspectivepada penerapan ERP lebih banyak dibahas dibandingkan dua kategori lainnya. Berikut ini perbandingannya dalam bentuk grafik.

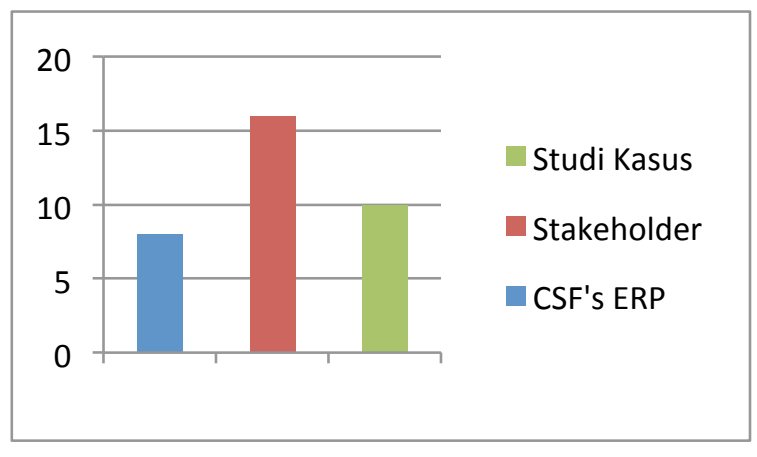

Gambar 3. Perbandingan Jumlah Masing-Masing Pengelompokkan

Dari hasil pengelompokan paper berdasarkan isi yang dibahas, maka akan didapatkan hasil dari tinjauan ulang yang akan membahas mengenai pengaruh stakeholder perspective dalam penerapan ERP dengan melihat dari tigasudut pandang yaitu 
studi kasus mengenai pengaruh stakeholder perspective dalam penerapan ERP, faktor-faktor dari stakeholder perspective yang berpengaruh pada proses penerapan ERP, dan solusi yang dapat digunakan dalam mencegah atau menangani masalah yang muncul berdasarkan faktor-faktor dari stakeholder perspective yang berpengaruh pada proses penerapan ERP.

\subsection{Studi kasus pengaruh stakeholder perspective dalam penerapan ERP}

Penerapan ERP pada perusahaan mempunyai banyak manfaat. Dengan menerapkan ERP, perusahaan mampu meningkatkan produktifitas perusahaan dengan cara mengurangi biaya pengeluaran dan meningkatkan pendapatan. Oleh karena itu, beberapa perusahaan mempunyai tujuan dalam penerapan ERP untuk mendapatkan banyak manfaat dari ERP. Namun beberapa studi kasus menunjukkan bahwa tidak semua penerapan ERP berjalan lancar dan sukses. Terdapat beberapa kegagalan pada penerapan ERP yang disebabkan oleh beberapa faktor. Beberapa studi kasus (Saini et al., 2013)(Shaul \& Tauber, 2012)(Finney, 2011)(Maguire et al., 2010)(Gallagher et al., 2012)(Drummond \& Araujo, 2016), menunjukkan peran stakeholder berpengaruh terhadap kesuksesan penerapan ERP. Hasil dari tinjauan studi kasus tersebut menunjukkan bahwa beberapa permasalahan yang timbul dari segi stakeholder adalah dari segi komunikasi yang kurang dan dukungan stakeholder. Faktor komunikasi dan dukungan stakeholder yang kurang menjadi perhatian dapat menimbulkan beberapa masalah dalam penerapan ERP yaitu, peran dan tanggung jawab stakeholder yang tidak terdefinisi dengan jelas, dan adanya konflik pada beberapa stakeholder yang terkait dalam proses penerapan ERP .

\subsubsection{Estimasi Biaya dan Durasi Waktu Penerapan ERP pada UKM}

Pada sebuah penelitian (Xie et al., 2014) mengatakan bahwa biaya dan durasi waktu proyek merupakan faktor yang sangat penting bagi UKM untuk dipertimbangkan sebelum mengadopsi sistem ERP, karena keterbatasan sumber daya dan proses yang kompleks. Xie et al, memperkirakan batas biaya dan durasi waktu yang digunakan pada penerapan ERP level UKM, dan strategi agar tidak terjadi pembengkakan biaya dan waktu penerapan ERP. Xie et. al, mengidentifikasi lima CSF yang berpengaruh terhadap biaya dan durasi waktu penerapan ERP, yaitu dukungan top management,pengguna, infrastruktur IT, project management, dan external expertise.

Menurut hasil penelitian Xie et. al, batas durasi proyek ERP pada UKM adalah kurang dari atau sama dengan 180 hari, dan batas anggaran proyek adalah 100.000 dollar. Hal ini didasarkan pada biaya dan waktu yang akan dihabiskan di setiap CSF agar kinerjanya dapat maksimal. Jika UKM bertujuan untuk mencapai tingkat kinerja yang lebih tinggi di akhir proyek tanpa menimbulkan biaya lebih, seharusnya perlu peningkatan kecepatan perkembangan tim yang menangani CSF. Sehingga perlu mengalokasikan sumber daya tambahan, termasuk lebih banyak komitmen dari top management, infrastruktur IT yang lebih maju, pelatihan staf yang lebih banyak, peningkatan jumlah anggota tim proyek, serta tingkat dukungan eksternal yang lebih tinggi.

\subsubsection{Kelebihan dan Kekurangan ERP}

Implementasi ERP tentunya memiliki kelebihan dan kekurangan dalam sebuah organisasi. Kelebihan tersebut dirasakan jika organisasi merasakan manfaat kompetitif dari implementasi ERP. Akan tetapi, kekurangan akan dirasakan oleh organisasi jika implementasi ERP tidak mendatangkan manfaat. Pada tabel 4 menjelaskan kelebihan dan kekurangan ERP.

Tabel 4. Kelebihan dan Kekurangan ERP

\begin{tabular}{|c|c|}
\hline Kelebihan & Kekurangan \\
\hline $\begin{array}{l}\text { Meningkatkan kualitas } \\
\text { keputusan manajer (Romero, } \\
\text { Menon, Banker, \& Anderson, } \\
\text { 2010) }\end{array}$ & $\begin{array}{l}\text { Mahal dan memakan waktu } \\
\text { yang lama dalam } \\
\text { implementasi (Romero et al., } \\
2010 \text { ) }\end{array}$ \\
\hline $\begin{array}{lr}\text { Meningkatkan } & \text { kepuasan } \\
\text { karyawan melalui } \\
\text { penghapusan redundansi dan } \\
\text { kerepotan dari } & \text { kegiatan } \\
\text { sehari-hari.(Barker } & \& \\
\text { Frolick, 2003) } & \\
\end{array}$ & $\begin{array}{l}\text { Perubahan budaya organisasi } \\
\text { (penolakan pengguna). } \\
\text { (Barker \& Frolick, 2003) }\end{array}$ \\
\hline $\begin{array}{l}\text { pemrosesan transaksi yang } \\
\text { lebih baik.(Barker \& Frolick, } \\
\text { 2003) }\end{array}$ & $\begin{array}{l}\text { Membutuhkan pelatihan } \\
\text { karena perubahan proses } \\
\text { bisnis yang signifikan } \\
\text { (Saade \& Nijher, 2016) }\end{array}$ \\
\hline $\begin{array}{l}\text { Mengurangi hambatan antara } \\
\text { departemen dan arus } \\
\text { pergerakan dari data kritis } \\
\text { masing-masing fungsi. } \\
\text { (Barker \& Frolick, 2003) }\end{array}$ & $\begin{array}{l}\text { Butuh perencanaan yang } \\
\text { matang (memakan sumber } \\
\text { daya yang banyak) (Bajahzar } \\
\text { \& Alqahtani, 2013) }\end{array}$ \\
\hline $\begin{array}{l}\text { Menyediakan informasi yang } \\
\text { terintegrasi (Saade \& Nijher, } \\
\text { 2016) }\end{array}$ & \\
\hline $\begin{array}{l}\text { Manajemen keuangan yang } \\
\text { baik dan transparan (Ali \& } \\
\text { Miller, 2017) }\end{array}$ & \\
\hline
\end{tabular}

\subsection{Faktor-faktor stakeholder perspective dalam penerapan ERP}

Berdasarkan hasil tinjauan dari beberapa studi kasus tentang pengaruh stakeholder perspective terhadap penerapan ERP, maka dapat disimpulkan bahwa terdapat 3 faktor penting pada stakeholder perspective dalam penerapan ERP. Faktor-faktor stakeholder perspective yang berpengaruh dalam penerapan ERP adalah komunikasi, dukungan stakeholder, dan kesiapan sumber daya manusia.

a. Komunikasi

Sebagai sebuah metode untuk memfasilitasi perubahan organisasi, stakeholder perspective 
menjadi salah satu faktor pendukung terbaik. Penerapan ERP adalah salah satu inisiatif perubahan yang sangat signifikan sehingga diperlukan upaya untuk menemukan skala pengukuran yang tepat untuk komunikasi yang efektif selama perubahan. Ada beberapa hal yang tidak diketahui dalam penerapan sebuah proyek ERP, yaitu lingkungan dan komunikasi yang lebih baik terhadap stakeholder dapat menyebabkan lebih banyak penerimaan dan pengurangan kekhawatiran terhadap sesuatu yang tidak perlu. Dengan adanya komunikasi yang efektif serta adanya strategi yang terstruktur dalam penyampaian informasi kepada karyawan membuat karyawan mengetahui apa yang sedang terjadi di perusahaan. Sehingga strategi komunikasi harus terkoordinasi agar dapat menjelaskan tujuan, jadwal, manfaat, dan gagasan serta laporan reguler ke tingkat eksekutor (Dezdar \& Ainin, 2011). Adapun strategi komunikasi untuk setiap stakeholder berbeda-beda. Sehingga komunikasi harus menggunakan pendekatan yang dapat menarik minat stakeholder (misal konten pesan yang berbeda, media yang berbeda, dan untuk kelompok yang berbeda), ini membuktikan bahwa kebutuhan kelompok stakeholder dipengaruhi oleh metode dan konten komunikasi agar memudahkan penerimaan perubahan (Finney, 2011).

\section{b. Dukungan Stakeholder}

Stakeholder merupakan orang-orang yang terlibat dalam penerapan sebuah system. Menurut sebuah penelitian menyatakan bahwa stakeholder perspective menjadi dasar mengenai keberhasilan penerapan ERP yang dapat dipertimbangkan (Nour et al., 2011).Stakeholder yang dimaksud adalah melingkupi top management dan tim proyek. Adanya dukungan stakeholder tersebut sangat berpengaruh pada kesuksesan penerapan ERP. Kebutuhan akan dukungan top management dan keterlibatan aktifnya sangat penting sehingga dapat membuat keputusan yang tepat, menengahi, menolak, menyelesaikan konflik, menunjuk tokoh yang berpikiran terbuka dan mendatangkan praktik dan pendekatan yang memadai (Shaul \& Tauber, 2012). Keterlibatan top management dalam setiap langkah penerapan ERP juga berdampak pada pengalokasian sumber daya yang berharga dalam upaya penerapan ERP (Dezdar \& Ainin, 2011). Selain adanya dukungan top management, juga penting adanya dukungan tim proyek yaitu dengan cara membentuk tim proyek yang profesional dengan divisi fungsional dan manajemen yang jelas untuk memfasilitasi kepemilikan aktif proyek (pengerjaan proyek ERP) (Shaul \& Tauber, 2012) .

\section{c. Kesiapan Sumber Daya Manusia}

Kesiapan sumber daya manusia dalam menerima adanya sistem ERP menjadi salah satu hal yang penting dalam mempengaruhi kesuksesan penerapan ERP. Pada suatu penelitian menyebutkan bahwa salah satu faktor keberhasilan kritis yang paling banyak dikutip dalam implementasi sistem ERP adalah partisipasi dan keterlibatan pengguna(Matende \& Ogao, 2013). Dengan melibatkan pengguna dalam tahap penentuan kebutuhan sistem informasi pada organisasi merupakan salah satu hal yang harus dipertimbangkan karena pengguna juga cenderung mengetahui kebutuhan organisasi, mereka bekerja sesuai dengan keahlian mereka di bidang fungsionalnya. Dengan melibatkan partisipasi pengguna, maka dapat memberikan kesempatan bagi pengguna untuk bereaksi positif terhadap potensi sistem ERP dan mengurangi adanya penolakan terhadap sistem ERP.

Salah satu penyebab kegagalan penerapan ERP pada perusahaan disebabkan karena adanya penolakan pengguna. Hal ini sering terjadi karena pengguna takut penerapan ERP akan mengubah kemudahan penggunaan, status pekerjaan, kepentingan, tanggung jawab, akses terhadap informasi berharga dan akhirnya keamanan kerja (Shaul \& Tauber, 2012). Kesiapan sumber daya manusia juga dapat dilihat dari tingkat pengetahuan pengguna. Tingkat pengetahuan pengguna yang minim mengenai sistem ERP dapat menghambat kesuksesan penerapan ERP. Dengan adanya pengetahuan yang dimiliki, maka dapat meningkatkan kemudahan penggunaan dan mengurangi hambatan pengguna, sehingga berpengaruh terhadap kesuksesan sistem ERP (Dezdar \& Ainin, 2011).

\subsection{Solusi}

Stakeholder perspective merupakan salah satu CSF pada penerapan ERP. Ada beberapa kasus yang terjadi pada penerapan ERP mengalami kesuksesan, namun ada juga beberapa kasus yang terjadi dalam penerapan ERP mengalami kegagalan. Berdasarkan faktor-faktor stakeholder persective yang mempengaruhi penerapan ERP, terdapat masalah yang muncul, seperti adanya stakeholder resistance, sertapenerapan ERP hingga over budget dan memakan waktu yang lebih lama atau molor. Oleh karena itu perlu adanya solusi yang dapat digunakan untuk mengatasi atau mengurangi masalah yang timbulberdasarkan faktor-faktor dari stakeholder perspective yang berpengaruh pada proses penerapan ERP. Berikut adalah solusi yang dapat digunakan dalam menangani stakeholder perspective agar tercapai keberhasilan penerapan ERP :

\section{a. Komunikasi}

Setiap informasi yang disampaikan kepada stakeholder harus jelas, sehingga tidak terdapat kerancuan informasi yang diterima oleh masingmasing stakeholder. Stakeholder dibedakan menjadi dua, yaitu internal yang meliputi manager, pegawai IT, dan pengguna, dan eksternal yang meliputi 
konsultan. Setiap stakeholder mempunyai culture yang berbeda, sehingga diperlukan cara komunikasi yang berbeda pada setiap stakeholder. Hal yang perlu diperhatikan dalam mengkomunikasikan penerapan ERP adalah media komunikasi dan konten komunikasi.

Konten komunikasi dalam penyampaian meliputi informasi yang harus diketahui oleh karyawan karena hal itu dapat mempengaruhi pekerjaannya, informasi yang harus diketahui oleh karyawan karena hal itu mempengaruhi beberapa aspek organisasi, dan informasi harus diketahui oleh karyawan untuk menghindariadanya gosip-gosip yang menyebar di kalangan kantor (Finney, 2011). Selain itu media komunikasi yang dapat dipakai adalah dengan cara bertemu atau bertatap langsung, melalui e-mail, teleconference, web page perusahaan, memo, serta media cetak(Finney, 2011).Salah satu tujuan dari komunikasi adalah untuk mendefinisikan peran dan tanggung jawab dari stakeholder. Namun adakalanya peran dan tanggung jawab stakeholder tidak terdefinisi dengan jelas, sehingga muncul perlawanan dari stakeholder yang dapat memicu kegagalan pada penerapan ERP. Oleh karena itu perlu mendefinisikan secara jelas peran dan tanggung jawab untuk setiap stakeholder. Morris (Morris \& Venkatesh, 2010), mendefinisikan job characteristic dapat berpengaruh pada job sastifaction, sehingga berpengaruh pada penerimaan oleh stakeholder. Adapun job characteristicini dapat digunakan untuk membantu mendefinisikan peran dan tanggung jawab stakeholder pada penerapan ERP. Job characteristic dikelompokkan menjadi lima, yaitu task significance, task identity, skill variety, autonomy, dan feedback.

\section{b. Dukungan Stakeholder}

Peran dukungan stakeholder terutama top management sangat berpengaruh dalam menyelesaikan konflik yang muncul. Top management sangat berperan penting dalam melakukan manajemen konflik, yaitu mengenali konflik yang terjadi pada stakeholder di setiap fase. Ketika top management telah mengenali konflik yang terjadi pada setiap fase evaluation and selection, initial setup, implementation, dan improvement, langkah selanjutnya adalah melakukan pertimbangan terhadap solusi yang akan digunakan. Salah satu cara yang bisa digunakan adalah melakukan negosiasi dengan stakeholder yang mempunyai konflik, sehingga dapat menemukan keputusan yang seimbang dan saling menguntungkan.

Menurut Mahmood Ali (Ali \& Miller, 2017), salah satucritical succes factor terpenting yang harus dipertimbangkan pada tahapan proses implementasi adalah tim proyek yang baik. Salah satu hal yang penting adalah membentuk tim proyek dengan divisi fungsional dan manajemen yang jelas untuk memfasilitasi kepemilikan aktif proyek. Sebagai tambahan, tim proyek harus diberi wewenang untuk mendefinisikan program yang jelas dan sumber daya yang dibutuhkan, menetapkan target waktu yang realistis dan memastikan kerjasama antardepartemen atau divisi(Shaul \& Tauber, 2012).

c. Pelatihan

Penerapan sistem ERP merupakan sebuah perubahan dalam suatu organisasi yang dapat berdampak pada penolakan. Sehingga perlu dilakukan pengelolaan perubahan sebaik mungkin untuk menghindari adanya penolakan. Salah satu aspek penting dalam pengelolaan perubahan adalah adanya pelatihan(Shah, 2011). Pelatihan bertujuan untuk memberikan edukasi kepada pengguna, agar pengetahuan yang dimiliki oleh pengguna mengenai sistem ERP dapat berkembang. Pelatihan ERP harus menangani semua aspek sistem, berkesinambungan, dan didasarkan pada prinsip transfer pengetahuan (Dezdar \& Ainin, 2011). Top management dan seluruh pengguna sistem harus sepenuhnya mengetahui mengenai sistem ERP, sehingga mereka mengetahui bagaimana sistem ERP diintegrasikan ke dalam keseluruhan operasi perusahaan dan semua pengguna harus dilatih untuk bisa memanfaatkan sistem ERP, sehingga manfaat penggunaan sistem ERP dapat dirasakan. Program pelatihan dilakukan secara terpisah untuk setiap unit organisasi berdasarkan posisi jabatan di dalam organisasi. Sebuah perusahaan dalam melakukan pelatihan bekerja sama dengan perusahaan konsultan yang menerapkan sistem ERP untuk mengembangkan materi pelatihan (Morris \& Venkatesh, 2010).

\section{KESIMPULAN}

Penerapan ERP pada organisasi mempunyai banyak manfaat. Sebelum memutuskan untuk menerapkan ERP, maka perlu mempertimbangkan estimasi biaya dan waktu, karena keterbatasan sumber daya dan proses yang kompleks. Adanya penerapan ERP, perusahaan mampu meningkatkan produktifitas perusahaan dengan cara mengurangi biaya pengeluaran dan meningkatkan pendapatan.Namun tidak selalu penerapan ERP mengalami kesuksesan, adakalanya penerapan ERP mengalami kegagalan sehingga menimbulkan beberapa kerugian. Perlu mempertimbangkan critical succes factor yang berpengaruh terhadap penerapan ERP, salah satunya critical success factor pada penerapan ERP adalah stakeholder. Oleh karena itu, perlu memahami adanya pengaruh stakeholder perspective dalam penerapan ERP.

Adapun faktor-faktor yang berpengaruh yaitu, komunikasi, dukungan stakeholder, dan kesiapan sumber daya manusia. Berdasarkan faktor-faktor tersebut, perlu mendefinisikan beberapa solusi yang dapat digunakan untuk mengatasi atau mengurangi masalah yang timbul. Solusi pertama yang dapat 
digunakan adalah mendefinisikan strategi komunikasi yang sesuai untuk menyampaikan informasi mengenai tahap-tahap proses penerapan ERP kepada masing-masing stakeholder, strategi komunikasi meliputi konten komunikasi dan media komunikasi. Solusi kedua adalah dengan memperkuat dukungan stakeholder yaitu top management dan tim proyek. Solusi ketiga adalah dilakukan pelatihan yang bertujuan untuk memberikan edukasi kepada pengguna, agar pengetahuan yang dimiliki oleh pengguna mengenai sistem ERP dapat berkembang.

\section{DAFTAR PUSTAKA}

Achimugu, P., Selamat, A., Ibrahim, R., \& Mahrin, M. N. R. (2014). A systematic literature review of software requirements prioritization research. Information and Software Technology, 56(6), 568-585. https://doi.org/10.1016/j.infsof.2014.02.001

Ali, M., \& Miller, L. (2017). ERP System Implementation in Large Enterprises - A Systematic. Journal of Enterprise Information Management, $30(4)$. https://doi.org/10.1108/JEIM-07-2014-0071

Alsulami, M., \& Scheepers, H. (2016). A Comparison between Organizational Stakeholders ' and External Consultants ' Perceptions on CSFs Affecting ERP Life. In Hawai International Conference on System Sciences (pp. 4676-4685). https://doi.org/10.1109/HICSS.2016.580

Bajahzar, A., \& Alqahtani, A. (2013). SUCCESSFUL IMPLEMENTATION OF ENTERPRISE RESOURCE PLANNING ( ERP ). In International Conference on Advanced Computer Science Applications and Technologies (pp. 156-160). https://doi.org/10.1109/ACSAT.2012.100

Barker, T., \& Frolick, M. N. M. N. M. N. (2003). ERP implementation failure: A case study. Information Systems Management, 20(4), 4349.

https://doi.org/10.1201/1078/43647.20.4.2003 0901/77292.7

Bintoro, B. P. K. (2015). Actors' interaction in the ERP implementation literature. Business Process Management Journal. https://doi.org/10.1108/BPMJ-11-2013-0142

Boonstra, A., \& Boonstra, A. (2016). How do top managers support strategic information system projects and why do they sometimes withhold this do they sometimes withhold this support? JPMA, 31(4), 498-512. https://doi.org/10.1016/j.ijproman.2012.09.013

Dezdar, S., \& Ainin, S. (2011). The influence of organizational factors on successful ERP implementation. Management Decision, 49(6),
911-926.

https://doi.org/10.1108/00251741111143603

Drummond, P., \& Araujo, F. (2016). Meeting halfway Assessing the differences between the perceptions of ERP implementers and endusers. Business Process Management Journal, 23, 936-956. https://doi.org/10.1108/MBE-092016-0047

Finney, S. (2011). Stakeholder perspective on internal marketing communication: An ERP implementation case study. Business Process Management Journal, 17(2), 311-331. https://doi.org/10.1108/14637151111122365

Gallagher, K. P., Worrell, J. L. J., \& Mason, R. M. (2012). The negotiation and selection of horizontal mechanisms to support postimplementation ERP organizations. Information Technology \& People, 25(1), 430. https://doi.org/10.1108/09593841211204326

Hogan, L. (2014). Critical success factors for ERP implementations Organizational view.

Maguire, S., Ab, O., \& Maguire, S. (2010). ERP implementation in Omantel: a case study. Industrial Management \& Data Systems, 110(1), 78-92. https://doi.org/10.1108/02635571011008416

Matende, S., \& Ogao, P. (2013). Enterprise Resource Planning (ERP) System Implementation: A Case for User Participation. Procedia Technology, 9, 518526. https://doi.org/10.1016/j.protcy.2013.12.058

Morris, M., \& Venkatesh, V. (2010). RESEARCH ARTICLE JOB CHARACTERISTICS AND JOB SATISFACTION : UNDERSTANDING THE ROLE OF ENTERPRISE RESOURCE PLANNING SYSTEM IMPLEMENTATION. MIS Quarterly, 34(1), 143-161.

Nour, M. a., Mouakket, S., Mohamed, a N., \& Samar, M. (2011). A Classification Framework of Critical Success Factors for ERP Systems Implementation: A MultiStakeholder Perspective. International Journal of Enterprise Information Systems (IJEIS), $7(1)$, 56-71. https://doi.org/10.4018/jeis.2011010104

Romero, J. A., Menon, N., Banker, R. D., \& Anderson, M. (2010). ERP: Drilling for Profit in the Oil and Gas Industry. Communications of the ACM, 53(7), 118. https://doi.org/10.1145/1785414.1785448

Saade, R., \& Nijher, H. (2016). Critical Success Factors in enterprise resource planning implementation - A review of case studies. Journal of Enterprise Information Management, 29(1), 72-96.

Saini, S., Nigam, S., \& Misra, S. C. (2013). 
Identifying success factors for implementation of ERP at Indian SMEs. Journal of Modelling in Management, 8(1), 103-122. https://doi.org/10.1108/17465661311312003

Shah, S. I. H. (2011). Exploring the Impediments of Successful ERP Implementation: A Case Study in a Public Organization. International Journal of Business and Social Science, 2(22), 289-296.

Shaul, L., \& Tauber, D. (2012). CSFs along ERP life cycle in SMEs: a field study. Industrial Management \& Data Systems, 112(3), 360384.

https://doi.org/10.1108/02635571211210031

Waiel AI-Rashid', M. A. M. A.-M. (2012). Exploring Enterprise Resource Planning (ERP) Implementation From Stakeholder Perspective - A Case Study. In The 5th International Conference on Communications, Computers and Applications (MIC-CCA2012) (pp. 12-14).

Xie, Y., James Allen, C., \& Ali, M. (2014). An integrated decision support system for ERP implementation in small and medium sized enterprises. Journal of Enterprise Information Management, 27(4), 358-384. https://doi.org/10.1108/JEIM-10-2012-0077 